\title{
POESIA VISUAL E DESIGN GRÁFICO: conexões
}

\author{
Amanda Tharen Marcondes Rezende \\ Universidade Estadual Paulista "Júlio de Mesquita Filho" \\ tharenmr@gmail.com \\ Cassia Leticia Carrara Domiciano \\ Universidade Estadual Paulista "Júlio de Mesquita Filho" \\ cassiacarrara@gmail.com
}

\begin{abstract}
Resumo: Este artigo apresenta o resultado de pesquisa onde foi realizado um levantamento histórico e uma breve análise dos contextos, relações e configurações da poesia visual através dos tempos, além de apresentar algumas tendências contemporâneas sobre o tema. Para isto, foi feito um levantamento bibliográfico, além da busca de informações, dados, imagens, trabalhos, enfim, textos diversos (verbais e visuais) sobre o tema, de modo a obter um resumo histórico crítico e acessível aos interessados. As relações entre a poesia visual e o design foram evidenciadas a fim de possibilita a produção de textos verbais e visuais e a publicação dos conteúdos pesquisados. Ao final, materiais visuais, um livro impresso e um blog foram criados para possibilitar o registro e a divulgação da pesquisa.
\end{abstract}

Palavras-chave: design gráfico, tipografia, design editorial, poesia visual.

\section{INTRODUÇÃO}

O envolvimento com o tema desta pesquisa deu-se quando se percebeu que as relações entre poesia visual e design gráfico são evidentes, porém pouco abordadas nos programas dos cursos graduação e pós-graduação em design. o conhecimento sobre a linguagem, sobretudo sobre a função poética da linguagem, representa ganhos expressivos do ponto de vista epistemológico e para os processos de criação em design, mas é algo que geralmente se sai da graduação sem aprender.

A poesia enquanto peça visual pode beneficiar-se dos mesmos elementos básicos de qualquer outro projeto de design em seu processo de criação e configuração, que segundo Lupton (2008) são: ponto, linha, plano, ritmo, equilíbrio, escala, textura, cor, figura/fundo, enquadramento, hierarquia, camadas, transparência, tempo e movimento; tudo isto, somado ainda às possibilidades linguísticas, torna a poesia visual uma linguagem rica e cheia de significado. Outro motivo que levou à pesquisa deste tema foi a dificuldade em encontrar bibliografias específicas sobre poesia visual e assuntos correlatos. Há também mais um importante fator a ser lembrado sobre este assunto: sua multidisciplinaridade que envolve o estudo e a 
exploração de diversas linguagens na sua criação e produção (poesia, diagramação, ilustração, tipografia, fotografia, animação, design gráfico/digital, e várias outras). Além disso, a poesia em si tem uma natureza muito mais artística que comercial.

O trabalho aqui apresentado englobou levantamento bibliográfico e documental sobre a poesia visual e suas relações com o design, culminando no desenvolvimento de produtos gráficos experimentais, na criação e editoração de um livro impresso e de uma mídia digital para postagens sobre o tema. Focou-se principalmente na poesia visual experimental, no âmbito da materialidade tipográfica e no uso da forma. Fez parte do processo uma pesquisa de Iniciação Científica e todo o material foi apresentado em projeto de final de curso no início de 2014, na Universidade Estadual Paulista - Unesp, campus de Bauru, curso de Design Gráfico.Uma breve apresentação do tema, dos objetivos, noções do referencial teórico, da metodologia e alguns pontos marcantes do trabalho.

\section{DESENVOLVIMENTO}

\subsection{Antecedentes}

A escrita nasceu da imagem. A prática da escrita iniciou-se com a representação através de desenhos e foi-se encaminhando para a abstração, através da invenção de signos para a representação de palavras e, posteriormente, sílabas. Segundo Caetano (2008) e Meggs (2009), este primeiro estágio da escrita é chamado pictográfico. Porém faltava a esse sistema icônico a capacidade de transmitir ideias mais abstratas. A partir desse sistema surge a escrita ideográfica, onde imagens simples foram associadas, permitindo a formulação de novos conceitos. Muitas línguas, como a chinesa, ainda hoje se utilizam do método ideográfico de escrita.
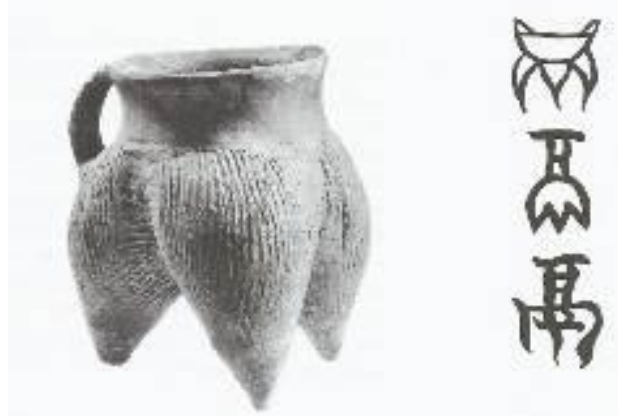

Figura 1 - 0 desenvolvimento do caractere ideográfico chinês Li (vasilha de cerâmica de três pernas), que hoje é a palavra para tripé.

Fonte: MEGGS, 2009, p.53.

Porém esses signos puramente ideográficos ainda não eram suficientes para representar alguns conceitos do pensamento. Foram então agregados ao sistema alguns elementos fonéticos. Assim também é o alfabeto ocidental: cada caractere representa um som. Com isso, ele está mais distante da representação pictórica que os ideogramas. Apesar disso, as formas que originaram cada caractere ainda possuem rastros imagéticos. 


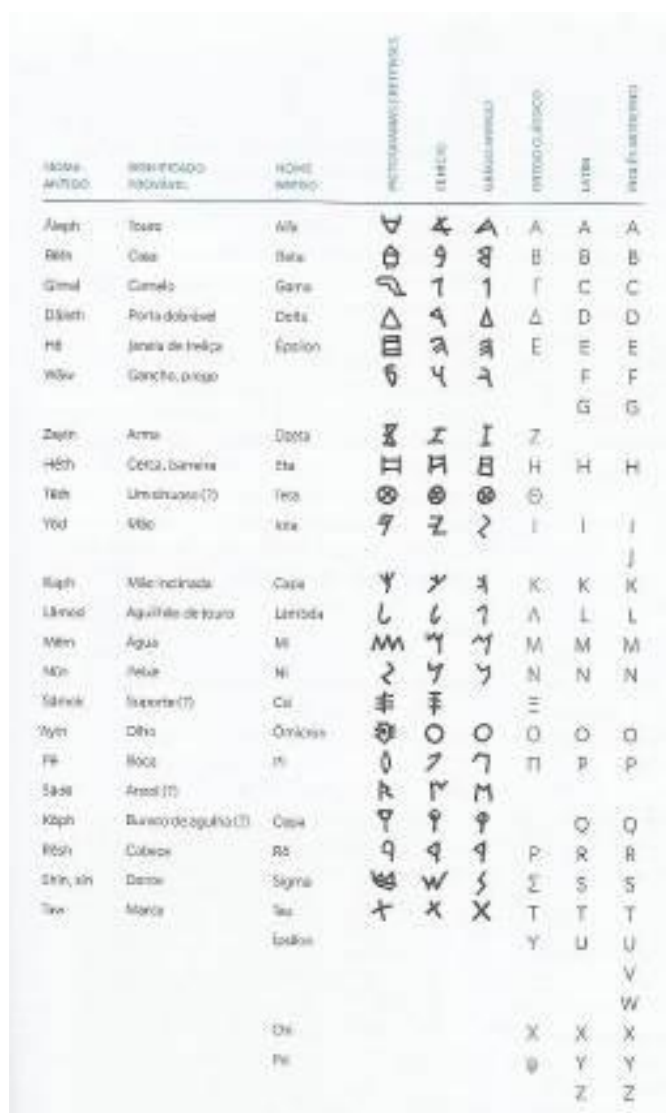

Figura 2 - Diagrama com as etapas de evolução dos alfabetos ocidentais e sua relação com os pictogramas.

Fonte: MEGGS, 2009, p.35.

Este nível de abstração da escrita alfabética faz com que, ao isolar-se uma letra do seu contexto, ela não remeta a nenhum sentido. A chamada "poesia visual" surge quando, além do verbal, outros códigos são utilizados na construção do sentido, possibilitando um universo mais amplo de linguagens.

Este sempre foi um desafio. Por isso, Miranda (2005) ressalta que para se compreender as bases da poesia visual, é importante lembrar que ela é, antes de qualquer outra coisa, uma tentativa de vencer o domínio da gramática, de romper com a ditadura da forma discursiva do poema, ou mesmo de superar a construção da prosa na poesia. Em entrevista concedida à autora em 2013, Omar Khouri, poeta, artista gráfico, editor, professor e crítico de linguagens, considera o termo Poesia Intersemiótica uma denominação perfeita para esse tipo de manifestação. Porém, foi o nome Poesia Visual - considerado por Khouri genérico e insuficiente - que ganhou força. Apesar disto, neste trabalho adotamos o segundo termo, já que enfocamos principalmente os aspectos gráficos da poesia.

O poeta sempre esteve sujeito a um formato na hora de inscrever um poema, mas não necessariamente sempre foi escravo de um. Temos, por exemplo, a obra "O Ovo" do poeta grego Símias de Rodes no séc. III a.C., o mais antigo poema visual que se tem notícia. Mas as experimentações com relação à forma até então não caracterizaram um movimento específico ou alcançaram notoriedade enquanto estilo. Foi apenas no séc. XIX que Guillaume Apollinaire (1898 - 1918) representou um marco na literatura francesa como um dos vanguardistas da poesia visual. Segundo Campos 
(2013), Apollinaire tornou-se conhecido por seus "caligramas", palavra que designa seis poemas escritos representando imagens, valendo-se da noção de "caligrafia" e de "ideograma", tendo sido empregada pela primeira vez pelo próprio poeta.

Outro nome de destaque no final de século XIX foi Stéphane Mallarmé, sobre o qual Miranda (2005) afirma que "já entendia que a poesia não ocupa apenas o espaço das palavras grafadas na "página em branco" mas todo o espaço circundante, inclusive os vazios. O espaço do poema é virtual, espaço-temporal". A estrutura do poema mallarmeano, semelhante a aspersão de palavras pelo espaço gráfico do papel, liquidava a noção de desenvolvimento linear onde há princípio, meio e fim. Ao invés disso, mostrava-se como verdadeira rosácea verbal. Seus poemas, juntamente com os de Apollinaire, seriam os primeiros alicerces sobre o qual se apoiaria posteriormente a poesia concreta brasileira.

\subsection{Movimentos modernistas internacionais}

Foi nos movimentos modernos em diversas partes do mundo que a Poesia Visual tomou forma. O primeiro deles a apresentar essa manifestação foi o Futurismo, inaugurado por texto publicado pelo poeta italiano Filippo Marinetti em 1909 no jornal parisiense Le Figaro. Surgiu como um movimento revolucionário em que todas as artes testariam suas ideias e formas contra as novas realidades da sociedade científica e cultural: o barulho e velocidade, duas condições dominantes da vida no século XX (MEGGS, 2009). A popularização do automóvel, a industrialização crescente, os aviões, as novas armas de guerra e a violência eram considerados a sinfonia da nova realidade humana. A partir disso, no campo da poesia, Marinetti e seus seguidores produziam um bombardeio visual que desafiava a sintaxe e a gramática corretas. A harmonia era rejeitada como qualidade do design porque era indiferente aos "saltos e explosões" de estilos que passavam a página. Na visão futurista, a vida urbana era muito melhor representada pelo caos, pelo dinamismo e pela não-linearidade.

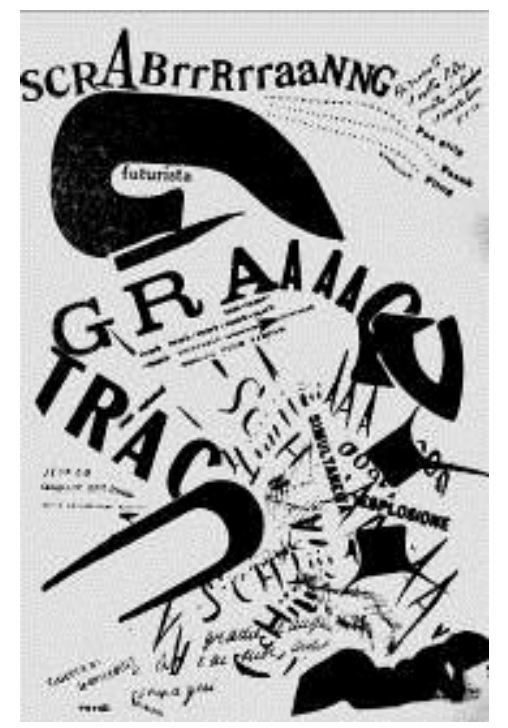

Figura 3 - Poema "Les Mots em liberte futuriste" (as palavras em liberdade futuristas), 1919, de Fillipo Marinetti

Fonte: Disponível em < http://www.philamuseum.org/collections/permanent/ 51449.html >. Acesso jun. 2013 
Outro movimento marcante foi o Dadaísmo, fundado por Tristan Tzara em 1916, na Suíça, como uma forma de rejeição à guerra e à falta de liberdade. Artisticamente falando, faz parte de um processo de ruptura com as concepções da estética clássica europeia, do qual participaram outros movimentos de vanguarda anteriores a ele, como o Expressionismo, o Fauvismo, o Cubismo e o Futurismo. Conforme escrito por Jorge et al. (2010, p. 2-3): "Eles tinham um denominador comum: a natureza combativa e a ruptura com a tradição estética, a busca por novas formas de expressão, e um desejo de libertação das amarras morais, políticas e religiosas (...) com a atitude lúdica e bem-humorada." Na literatura, o movimento se traduzia na destruição da forma e do significado lógico. Essa liberdade de criação influenciou os designers gráficos ajudando a libertá-los das restrições retilíneas e considerando o uso da letra em si mesma como uma experiência visual. A superação da apatia visual através do uso do surpreendente e do anárquico era de extrema importância. Segundo Watanabe (2009), o dadaísta Kurt Schwitters desenvolveu várias experiências na tipografia que se direcionaram para o Construtivismo. Uma de suas propostas foi o Systemschrift, onde o artista criou as letras denominadas "optofonéticas", que consistem em caracteres diferentes para cada som.

\author{
ARChIтYPe 5twitTens

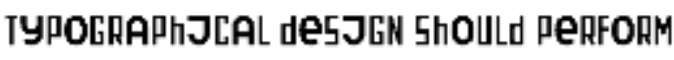 \\ OPTICALLy What the 5Peaken cReates \\ ThRough VaICE ANd Gestune Fon hl5 ThDught5. \\ eL LI55JTZKY
}

\title{
HALCDECFEhIJ]KLMND OPQR55TUUVWXXYZ马5 5口E\&E1234567890
}

Figura 4 - Systemchrift de Kurt Schwitters

Fonte: Marin Šantic, 2011. Disponível em < http://www.marinsantic.com/ eksperimentalna-tipografija-20-stoljeca/ > . Acesso set. 2013.

Outro destaque foi Ezra Pound (1885 - 1972), poeta, músico e crítico literário americano. Segundo o site Academy of American Poets (2013), nas primeiras décadas do século XX, Pound interessou-se por trabalhos sobre os ideogramas chineses, em especial um ensaio chamado "The Chinese Written Character as a Medium for Poetry", analisando especialmente a relação entre o visual e o textual contida nos mesmos. Em 1914, Pound lançou nos Estados Unidos e Londres uma escola estética modernista a qual chamou de "imagismo", em que defendia o uso da linguagem coloquial, a criação de novos ritmos sonoros ultrapassando a métrica, liberdade na escolha do assunto, verso livre, poesia clara e apresentação de imagens. Mais tarde, Ezra Pound foi levado a fundar uma outra teoria estética - o vorticismo - de caráter experimental, marcadamente influenciado pelo futurismo. Considerava-se o futurismo 
essencialmente uma aceleração de imagens sucessivas, como o "Nu descendo as escadas", de Marcel Duchamp; já o vorticismo ampliava essa aceleração em profundidade, criando um turbilhão de perspectivas, ou seja, um vórtice. No vorticismo, o escritor manteve diversos aspectos do imagismo e adicionou uma determinada estilização gráfica em seus poemas, que podem ser considerados como precursores da poesia concreta. Um grande veículo do vorticismo foi a revista BLAST, publicada em duas edições - em 1914 e 1915.

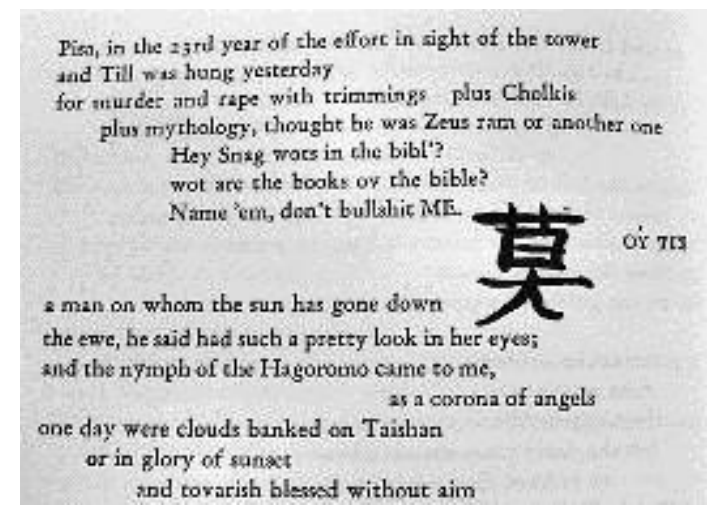

Figura 5 - Poemas de Ezra Pound evidenciando a relação com os ideogramas chineses

Fonte: Website WORDSMIRCH. Disponível em: < http://wordsmirch.flim.com/post/ 31733111984/ezra-pound-the-cantos-new-york-new-directions >. Acesso jun. 2013

Outro importante nome a ser citado no imagismo é o do americano E.E. Cummings (1894 - 1962) - ou e.e.cummings, como ele preferia grafar. Segundo MÜLLER \& DOMINGUES (2005), o poeta empreendeu no uso de recursos gráficos, cujos poemas poderiam ser comparados ao Un coup de dés, de Mallarmé, aos Cantos de Pound, e aos Calligrammas de G. Apollinaire.

I(a
le
af
fa
Il
s)
one
1
iness

Figura 6 - Poema de E. E. Cummings

Fonte: MÜLLER e DOMINGUES, op. cit.

Contemporâneo de Pound e Cummings, o poeta irlandês James Joyce (1882 1941), também contribui grandemente para o desenvolvimento da literatura; 
especialmente na poesia, pela criação do conceito de "verbivocovisual" ${ }^{1}$, do qual se apropriariam os poetas brasileiros posteriores a ele. Os primeiros poemas de Joyce, "Música de Câmara" (em 1907), feitos para serem letras de música, continham, no entanto, uma visualidade e objetividade que os aproximavam do imagismo de Pound, o qual defendia e elogiava seu trabalho. Assim, Joyce foi considerado um dos mais eminentes poetas desta escola literária.

Outro movimento artístico moderno, o De Stijl, teve uma influência importante na poesia visual. Nasceu na Holanda em 1917. Buscavam-se leis universais de equilíbrio e harmonia para a arte, através de um estilo geométrico abstrato. Meggs (2009) considera que seu fundador foi Theo van Doesburg, a quem mais tarde se juntaram arquitetos e artistas como o famoso pintor Piet Mondrian. As pinturas de Mondrian formam a base sobre a qual se desenvolveram a filosofia e as formas visuais do movimento. Inspiradas nos pensamentos do filósofo $M$. H. Schoemakers sobre o conflito universal entre horizontal e vertical, as obras do movimento também foram marcadas pelo uso do vermelho, amarelo e azul como cores básicas. Seus adeptos acreditavam na beleza da impessoalidade, da ordem matemática e na pureza absoluta da obra através desses critérios, a fim de criar soluções coletivistas. $O$ espírito do De Stijl viria mais tarde a inspirar a poesia concreta brasileira, ao ponto de Augusto de Campos (um dos principais nomes do concretismo) criar seus poemas como uma fórmula matemática, gerando uma arte de fato impessoal e com um resultado praticamente abstrato.

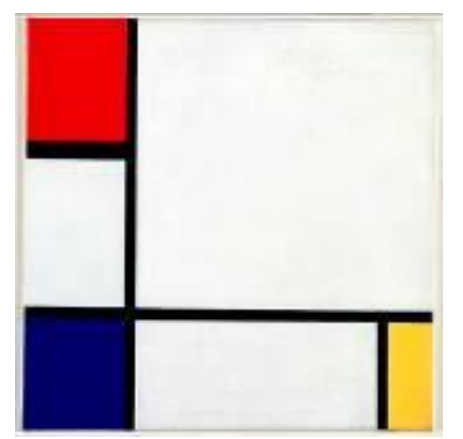

Figura 7 - Obra "Compositie $n^{\circ}$ IV met rood, blauw en geel" (composição $n^{\circ}$ IV com vermelho, azul e amarelo), de Piet Mondrian, 1929.

Fonte: Website Online teaching support. Disponível em: < http://creatixs. wordpress.com/ki/schilderen/ > Acesso jun. 2013

O papel da Bauhaus também se destaca nessa história. Segundo Teixeira (1997), no ano de 1919, na cidade alemã de Weimar, o arquiteto Walter Gropious determinou a junção das duas escolas que lá existiam: a Escola de Artes e Ofícios e a Escola de Belas Artes, que vieram a formar a célebre Staatliches Bauhaus. Um de seus propósitos era integrar artesãos e artistas (que até então ocupavam espaços distintos), e também a arte com a indústria. Revolucionou o design moderno ao buscar formas e linhas

1 “(ver.bi.vo.co.vi.su:al): Na poesia concreta, diz-se da forma de apresentação de um poema em que o texto é organizado segundo critérios relacionados aos aspectos gráficos e fonéticos das palavras; integração do verbal, do visual e do sonoro: a dimensão verbivocovisual da poesia." (DICIONÁRIO AULETE, 2013). 
simplificadas, definidas pela função do objeto. A geometrização e funcionalismo da Bauhaus influenciaram profundamente a criação em variadas áreas do design gráfico.

"Podemos observar as questões colocadas pelos poetas Marinetti e Mallarmé também nos trabalhos de Johannes Itten, professor da Bauhaus, em 1921. O mestre da escola de artes e ofício de Weimar, com objetivos de dar ênfase e inflexão às palavras contidas no texto impresso, aplicava as técnicas utilizadas pelos futuristas para articular os tipos de impressão." (WATANABE, 2009)

Conforme Souza (2013), na tipografia um de seus grandes nomes foi Herbert Bayer (1900 - 1985), autor do alfabeto universal "Sturm Blond", reduzido às formas mais simples possíveis e sem diferenciação de maiúsculas e minúsculas. Para Bayer, já que a palavra falada não faz distinção entre caixa baixa ou alta, tal diferenciação no texto escrito também não se fazia necessária.

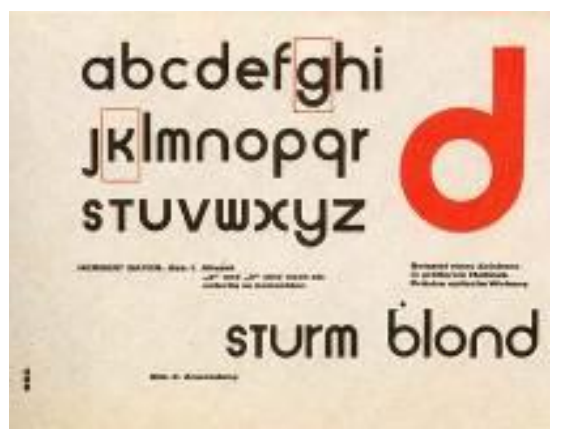

Figura 8 - Alfabeto Sturm Blond, criado por Herbert Bayer em 1925.

Fonte: Website Bauhaus-archiv. Disponível em: < http://www.bauhaus.de/ bauhaus1919/werkstaetten/werkstaetten typographie.html > Acesso jun. 2013.

Com isso notamos, mais uma vez, a preocupação em não dissociar o aspecto sonoro da língua escrita - um reforço ao conceito de "verbivocovisual" criado por James Joyce e que seria fundamental na poesia concreta brasileira. Mas talvez o maior mestre da Bauhaus por sua influência no design gráfico seja Jan Tschichold (1902 - 1974). Ele publicou em 1928 sua famosa obra "Die neue typographie", uma ruptura com o modelo tradicional de configuração da página através de formas derivadas da função do texto; uso da assimetria; valorização dos espaços brancos; uso de contrastes; e escolha racional das cores.

A última, mas não menos importante, foi a influência do Construtivismo, movimento ocorrido na Europa nos anos 20 e 30, principalmente na Rússia. Inicialmente influenciados pelas conferências de Marinetti, os artistas russos posteriormente seguiram adiante para outras inovações. A produção seria baseada em ciência e técnica, em lugar de especulações subjetivas. "Liderados por Vladímir Tátlin (1885 - 1953) e Aleksandr Ródtchenko (1891-1956), 25 artistas [...] renunciaram à 'arte pela arte' para se dedicar ao design industrial, comunicações visuais e artes aplicadas a serviço da nova sociedade comunista" (MEGGS, 2009, p. 374). Uma das metas do construtivismo era unir em peças gráficas palavras e imagens, numa experiência simultânea e revolucionária. Estas composições palavra-imagem eram o 
primeiro passo para o fotojornalismo. Apenas após a 2a Guerra Mundial a influência do construtivismo na poesia ganharia força, onde alcançaria várias partes do mundo e receberia o nome de Poesia Concreta.

\subsection{0 cenário brasileiro}

A exploração do grafismo na poesia chegou ao Brasil apenas nos primeiros anos do século 20, inspirando poetas brasileiros na conformação do que mais tarde seria chamado de Poesia Concreta - e que, segundo Campos (2012), viria a afirmar-se como movimento somente a partir da década de 1950. Nesta época havia um ambiente estimulante para o desenvolvimento de sugestões renovadoras nas artes: durante o governo de Juscelino Kubstchek, uma nova arrancada tecnológica ocorreu no interior de um processo de remanejamento das relações internacionais. Amaral (2013) considera que a partir de então a sociedade adquiria feição urbana, e as artes em geral voltavam-se para o espírito da invenção e da radicalidade dos grandes movimentos de vanguarda do início do século. Quanto à maneira como a poesia concretista se relacionava com a nova configuração social, nos temas da poesia concreta brasileira observamos a conciliação entre humor e crítica social, tal como no exemplo do poema "Beba Coca-cola" de Décio Pignatari. Os poemas frequentemente faziam crítica direta às tendências de globalização e consumismo cada vez mais crescentes.

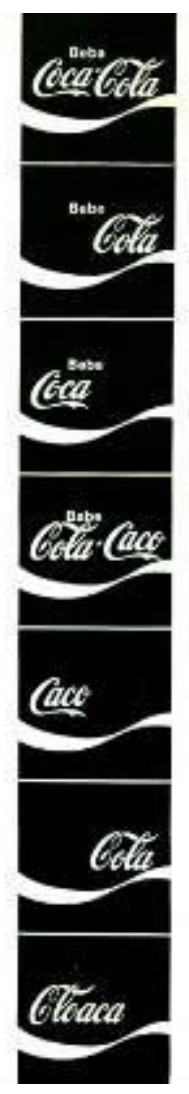

Figura 9 - Poema "Beba Coca-cola..." (1957), de Décio Pignatari - tradução visual de Régis Bonvicino, 1979.

Fonte: Transcriar - website Antonio Miranda. Disponível em: < http://www.antoniomiranda.com.br/poesia visual/transcriar.html $>$. Acesso jun. 2013. 
O primeiro grande movimento brasileiro foi o concretismo, que se destacou pelo desenvolvimento de novas figuras de poesia associadas à criação plástica. Em São Paulo, Décio Pignatari e os irmãos Augusto de Campos e Haroldo de Campos haviam iniciado pesquisas sobre novas formas de expressão poética - sendo os irmãos Campos fortemente influenciados pela obra de Ezra Pound, principalmente no que diz respeito aos estudos da poesia japonesa e o conceito de ideograma. Segundo Amaral (2013) e Schenberg (1977), eles iniciaram o grupo e publicaram a revista Noigandres em 1952, ainda antes do aparecimento do movimento concretista de São Paulo. Depois houve aproximação entre os poetas e artistas visuais. O segundo número da Noigandres (1955) continha a série de poemas Poetamenos, escritos em 1953 por Augusto de Campos e considerados os primeiros exemplos consistentes de poesia concreta no Brasil. As palavras eram rearranjadas em estruturas gráfico-espaciais, algumas vezes impressas em até seis cores diferentes, abandonando o verso e a sintaxe convencional sob inspiração da Klangbarbenmelodie (melodia de timbres) do músico Anton Webern: "Uma melodia contínua deslocada de um instrumento para outro, mudando constantemente sua cor." (CAMPOS et al., 1975). O próprio Augusto de Campos (1975, p. 44) relata que Mallarmé, Joyce, Cummings, Apollinaire e as tentativas experimentais futuristas-dadaístas estavam na raíz do novo procedimento poético que tende a impor-se à organização convencional do verso (livre inclusive).
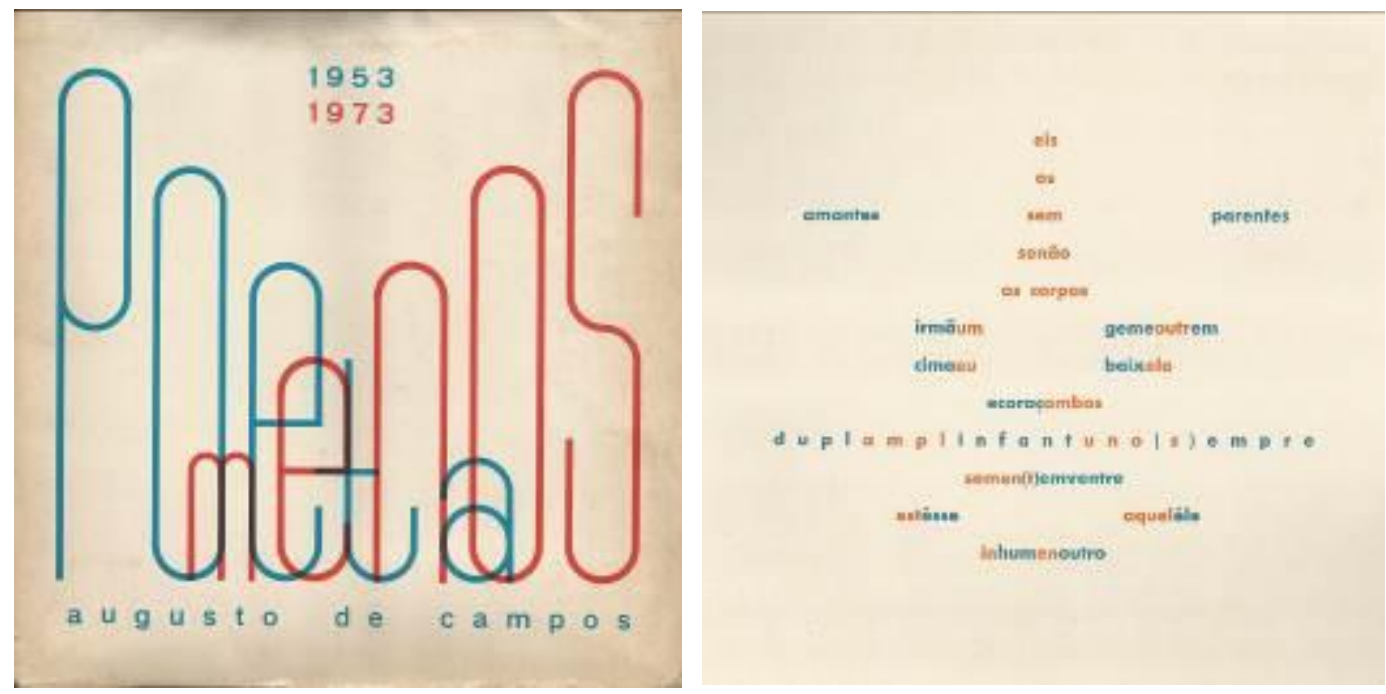

Figura 10 - Capa e poema da série Poetamenos, previsto para 2 vozes-cores, masculina e feminina.

Fonte: Acervo Memória Visual José Luiz Valero Figueiredo

Segundo Secchin (1991), após este núcleo Noigandres vieram os seguidores Pedro Xisto, José Lino Grünewald, Ronaldo Azeredo, que organizaram-se em torno da revista INVENÇÃO. A partir de 1962, a revista atingiria cinco números. O poeta Paulo Leminski (1944 - 1989), estreou em 1964 com cinco poemas na revista INVENÇÃO, dirigida por Décio Pignatari, em São Paulo. A relação de Leminski com as experimentações visuais é exemplificada em seu livro-arte Winterverno, de 2001 uma parceria com o poeta e artista João Suplicy, onde há uma combinação de textos 
de Leminski com as imagens do artista plástico na configuração de haigas, ou poemasdesenhos - a categoria mais plástica da poesia oriental.

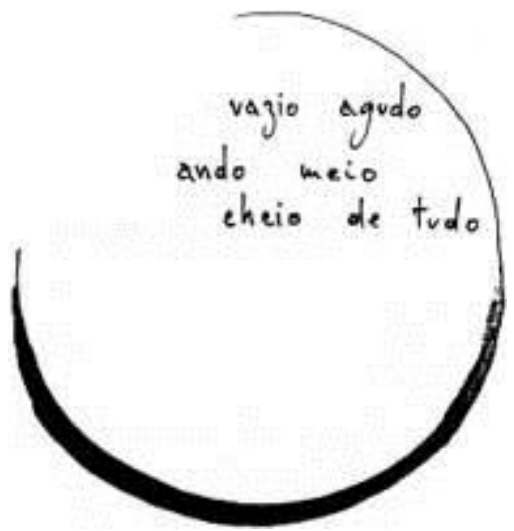

Figura 11- Poesia visual de Leminski e Suplicy

Fonte: Acervo Memória Visual José Luiz Valero Figueiredo. Disponível em: < http://revistamacondo.wordpress.com/2012/03/27/os-desenhos-dos-escritores-3/ $>$. Acesso jun. 2013.

A poesia concreta foi tão marcante, que ainda hoje é confundida com o termo "poesia visual" de modo geral. No entanto, nem toda poesia visual é poesia concreta isto porque há uma série de itens que caracterizam a poesia concreta como tal: a eliminação do verso; o aproveitamento do espaço em branco da página para disposição das palavras; a exploração dos aspectos sonoros, visuais e semânticos dos vocábulos; o uso de neologismos e termos estrangeiros; decomposição das palavras; possibilidades de múltiplas leituras.

No Rio de Janeiro, um grupo de dissidentes do concretismo representado principalmente por Ferreira Gullar, e também Theon Spanoudis em São Paulo, desenvolveram outras formas de poesia, que chamaram Neoconcreta (Schenberg op. cit.). Gullar defendia que a poesia visual deveria reaproximar-se da intuição do autor e do sentimento do leitor, ao invés de seguir em rumo a uma arte não-figurativa impessoal e abstrata; além disso, a estruturação do poema no espaço e superação do verso como unidade rítmico-formal não deveria limitar-se ao uso do espaço bidimensional.

"Para melhor entendermos o que se passou na arte neoconcreta, é necessário nos voltarmos para o trabalho dos poetas, que não se limitaram às composições 'verbivocovisuais' do grupo paulista, mas enveredaram por outros caminhos, que valorizavam mais o livro do que a página como o veículo do poema. Em função disso, nasceu o livro-poema, criado por mim, em 1959, que teve influência decisiva no desdobramento de todo o movimento, ao introduzir a participação do espectador (no caso, o leitor) na obra de arte, um traço particular da arte neoconcreta." (MANIFESTO NEOCONCRETO, 1959). 


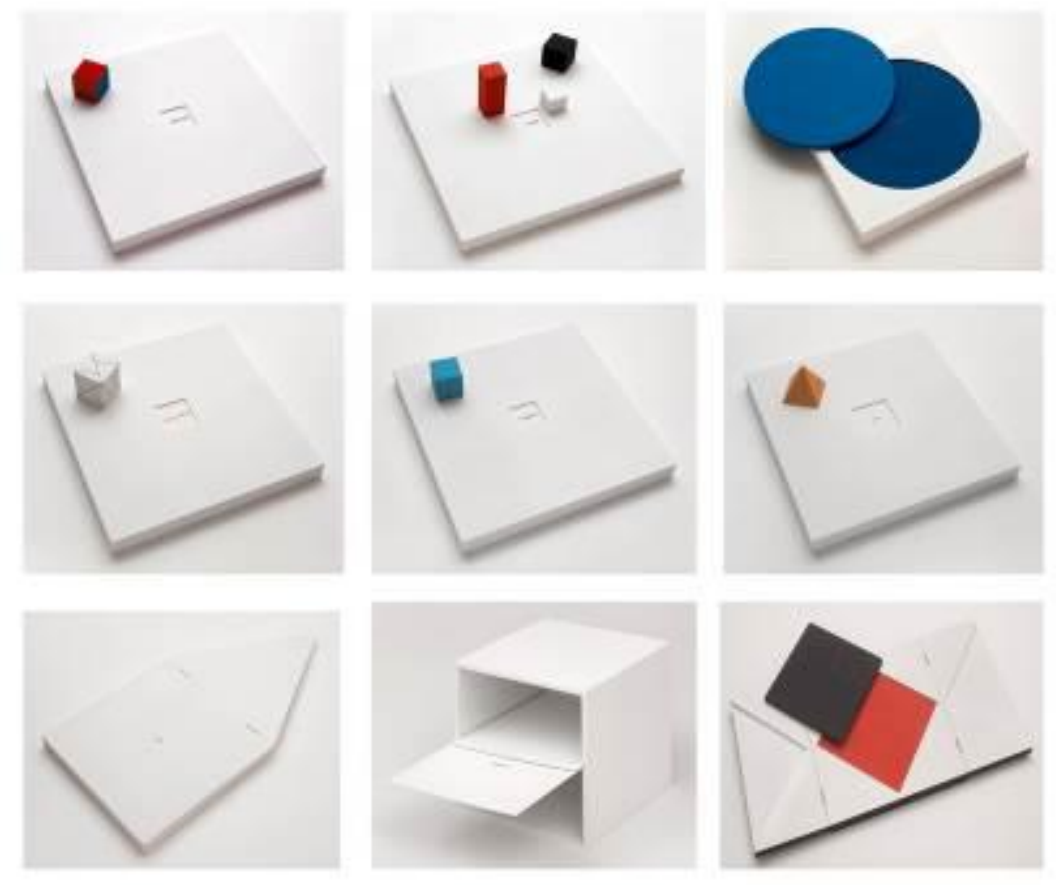

Figura 12- Poesia da fase neoconcreta de Ferreira Gullar

Fonte: Website Concretos Paralelos. Disponível em: < http://www. concretosparalelos.com.br/?p=984 >. Acesso jun. 2013.

\subsection{Panorama contemporâneo}

Certamente a poesia visual contemporânea vem lutando no cenário artístico para ganhar a merecida atenção. Há um crescente esforço na realização de encontros nacionais e internacionais para mostrar o que tem sido feito. Observa-se uma tendência do uso da plataforma digital como ferramenta de elaboração e reprodução das poesias, tendo em vista que permite muito mais possibilidades ao artista.

Uma ação que se iniciou em 1974 - em Pirajuí, interior, e depois São Paulo, capital - e subsiste na contemporaneidade é a revista ARTÉRIA, editada pela Nomuque Edições. Segundo Khouri (2011), entre as revistas mais empenhadas com a experimentação, foi ARTÉRIA a que mais se metamorfoseou, a que com o passar do tempo mais se especializou na poesia intersemiótica e/ou intermídia. Desde o seu princípio, a revista tem por objetivo o uso de diversos suportes, e não apenas papel. Ainda hoje é possível encontrar na internet a ARTÉRIA 8, uma publicação digital que desde o ano 2003 reúne poesias visuais e animadas de cerca de 40 participantes e está em constante atualização e crescimento. A revista conta também com edições "tradicionais", a exemplo da revista ARTÉRIA 6, impressa toda em serigrafia, e a ARTÉRIA 7 (AR7ÉRIA), feita em offset. 


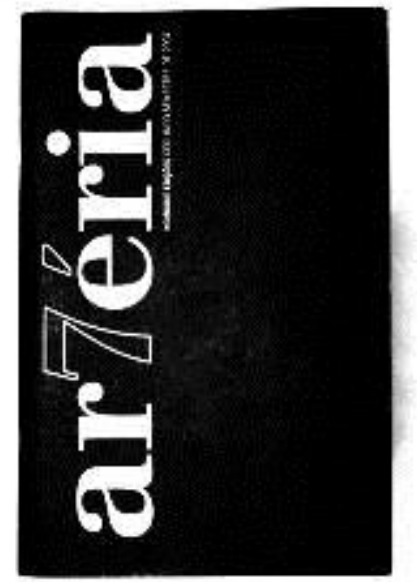

Figura 13- Capa da revista Artéria 7

Fonte: Revista Artéria 7, 2004.

A última edição publicada foi a Artéria X, lançada em maio de 2011. Quanto às perspectivas futuras da Nomuque Edições e da revista ARTÉRIA, Omar Khouri comentou em entrevista:

“A Nomuque Edições, que existe desde 1974 [...] tem feito muito pouco - a última 'grande façanha' foi ARTÉRIA X, lançada em maio de 2011. Mas tem participado de feiras que comportam o tipo de trabalho que faz. Pretendem, os editores, fazer pequenas tiragens de trabalhos de Poesia Visual e afins, fundamentalmente, e realizar uma ARTÉRIA 11, que seria, em verdade, uma exposição, com trabalhos de 22 poetas, talvez objetos únicos. Pode ser que venhamos a fazer pequenas tiragens de pequenos livros e álbuns, em reprografia e serigrafia. As pequenas edições são mais prováveis, pois não exigem muito dinheiro [...]."

É comum hoje que poetas utilizem as plataformas digitais para exposição de seu acervo. Quanto a isto, Omar Khouri faz a seguinte ressalva:

"Bem, todos dizem com orgulho e vaidade que possuem um site etc etc etc. Porém, na maior parte das vezes, principalmente os que atuam como artistas/poetas, não sabem muito bem do que se trata, do que cabe na REDE ou do que pode simplesmente ser da conta de um livrinho tradicional, de uma simples carta ou de uma conversa informal. É preciso adequar a linguagem, é preciso pensar em termos de internet, ou seja, em termos planetários. Um poema na internet deve ser aquele que visa a um público certo/incerto [...]. Destinatários de um poema da REDE: terráqueos do Brasil, da Rússia, do Japão, do Líbano, do Vietnã [...]” (KHOURI, 2011).

Pode-se identificar, por um lado os artistas que apenas aproveitam o alcance global proporcionado pelo meio digital como mais uma possibilidade de divulgação e, por outro lado, outros que o utilizam como finalidade real da poesia, configurando o que foi 
denominado de "poesia eletrônica". Segundo Antonio (2005), este tipo de poesia pode ser formada de palavras, formas gráficas, imagens, sons, elementos animados ou não, na maior parte das vezes interativos, hipertextuais e/ou hipermidiáticos, formatados pela linguagem de programação dos computadores e que constituem um texto eletrônico, um hipertexto e/ou uma hipermídia. Ela existe no espaço simbólico do computador (internet e rede), tendo como forma de comunicação poética os meios eletrônicodigitais que se vinculam a esses componentes. De um modo geral, ela só existe nesse meio e só se expressa, em sua plenitude, por meio dele.

\subsection{Retomada da caligrafia}

Outro recurso retomado na contemporaneidade é o da caligrafia. Assim como o uso do espaço gráfico, as cores, variações nos caracteres, alterações no sentido de leitura, animação e etc. são formas de construção da poesia visual, a caligrafia também pode constituir-se como um recurso importante para o artista. Vemos que na caligrafia o próprio ato da escrita e o seu resultado espontâneo fazem parte da obra, sendo o traço como uma marca digital deixada pelo autor. Assim, o traço que compõe a escrita abre diversas possibilidades expressivas, facilitando a transferência de uma determinada intenção comunicativa. Segundo Meggs (2009), As poesias mais antigas (bem como qualquer outro tipo de texto) necessitavam da caligrafia, já que o manuscrito era o principal meio de produção de livros existente antes da invenção dos meios de impressão. Hoje, a caligrafia não tem mais essa função; no entanto, devido às suas qualidades expressivas citadas anteriormente, ela tem sido resgatada e utilizada por muitos artistas, a exemplo dos brasileiros Ruth Arbernaaz e Arnaldo Antunes, onde a caligrafia confere às obras destes artistas singularidade e intimidade.

Arnaldo Antunes é um renomado artista do cenário brasileiro, atuando em diversas áreas como a música, literatura e artes gráficas. Também é um dos participantes da revista ARTÉRIA (citada anteriormente neste artigo), realiza experimentos com caligrafia e possui diversos livros publicados sobre poesia em suas diversas formas, incluindo a poesia visual.

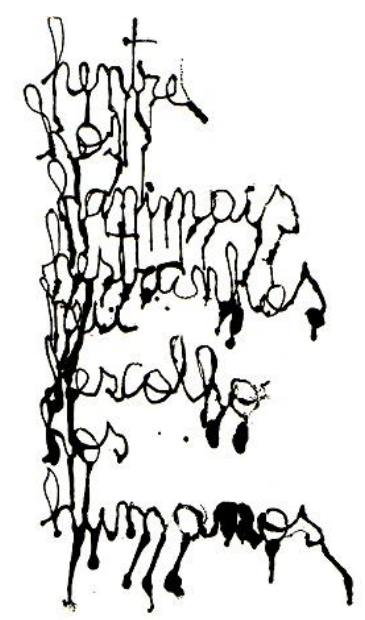

Figura 14- Cacografia de Arnaldo Antunes

Fonte: Website Arnaldo Antunes. Disponível em: < http://www.arnaldo antunes.com.br/new/sec artes obras.php?id type=1 >. Acesso jun. 2013. 
Algumas de suas obras são dedicadas especialmente ao público infantil, lembrando-nos de outra característica importante da poesia visual: o aspecto lúdico, alcançado ao permitir que os caracteres, palavras e versos rompam com a estrutura tradicional do texto. No entanto, a poesia visual enquanto recurso nos livros infantis não é uma tendência contemporânea. Meggs (2009) recorda que, no livro "Alice in Wonderland" (Alice no País das Maravilhas) de 1866, já temos uma inesperada imagem tipográfica diferente de todas as demais páginas: o autor Lewis Carroll utiliza o texto para compor o desenho de uma cauda de rato. Na época, o livro foi aclamado pela crítica.

Ruth Albernaaz é uma bióloga e artista plástica de Curitiba. Muitas de suas obras são voltadas à poesia, mais especificamente à sua apresentação através de uma linguagem muito particular: Ruth não só se aproveita do espaço do papel, mas também aplica sua própria caligrafia informal na transcrição dos versos, além de usar outros materiais encontrados na natureza, como sementes, folhas, etc.

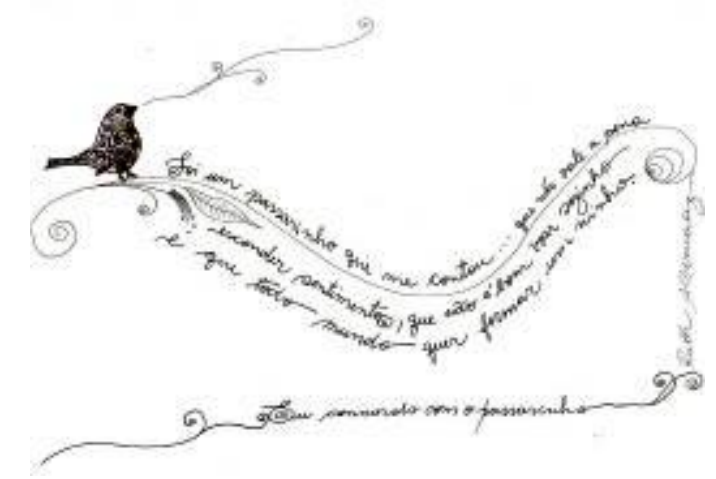

Figura 15- Poesias visuais de Ruth Albernaaz

Fonte: Website Ruth Albernaaz. Disponível em: < http://ruthalbernaz.blogspot. com.br >. Acesso jun. 2013.

Ainda no contexto da escrita manual como ferramenta para exteriorizar a poesia, tem-se o projeto "Eu me chamo Antonio" criado pelo publicitário Pedro Gabriel, de 29 anos, que atualmente vive no Rio de Janeiro. Suas peças (inicialmente produzidas numa mesa de bar) consistem em poesias e filosofias de botequim que estampam guardanapos. Algumas se utilizam da ilustração e recursos visuais como a caligrafia e lettering, enquanto outras exploram os jogos de palavras; mas a maioria visa unir as duas coisas gerando poesias visuais extremamente originais e sensíveis que alcançaram rápido sucesso em sua página no Tumblr e Facebook.

\subsection{Relações com o design gráfico}

A este ponto de desta investigação, já se pode vislumbrar as muitas possibilidades de relação da poesia com o design e diferentes naturezas que esta relação possui. Omar Khouri (in: CAETANO, 2008) considera que a relação poesia/olho pode dar-se de três modos: 1) provocar no leitor a formação de uma imagem mental; 2) 
o poema adquirir dimensão visual através da própria materialidade da escrita; e 3) a visualidade a partir do emprego de recursos visuais.

Quanto ao primeiro item, a formação de uma imagem mental, é um fenômeno que se dá principalmente a partir da linguagem oral ou escrita, onde a imaginação e interpretação do texto possibilitam ao leitor a criação de um cenário mental. Ou seja, tem caráter especialmente verbal e se dá a partir da decodificação semântica do conteúdo textual. O poeta imagista Ezra Pound dava a esse fenômeno o nome de "fanopéia" (in: CAETANO, op. cit). Os textos imagistas, mesmo quando não ousavam graficamente, possuíam esta como a sua principal intenção poética.

Já o uso da materialidade da escrita talvez seja um dos campos mais férteis para o entrelaçamento design gráfico/poesia, por isso é um dos principais focos desta pesquisa. Além disso, é um dos modos preferidos (ou mais "tradicionais") de se fazer poesia visual pelos artistas acostumados ao verso. A materialidade da escrita pode ser explorada de diversas maneiras, como a forma tipográfica, cor, alinhamentos, espaçamentos, a escrita caligráfica e até mesmo o registro do gesto da escrita. A inserção destes elementos icônicos, cheios de significado, enriquece a mensagem tanto na poesia quanto no design. Este recurso é muito utilizado nas criações publicitárias e de logotipos. Aqui entram também os trabalhos de lettering, onde a manipulação tipográfica agrega sentido à mensagem.

A visualidade a partir de recursos visuais, refere-se, por exemplo, aos desenhos, texturas, elementos gráficos, projeções luminosas, etc. Aqui tais elementos não fazem parte do texto propriamente dito, mas podem ser agregados a ele a fim de lhe aumentar as possibilidades de interpretação. Algumas poesias visuais até mesmo aboliram o uso verbal, sendo que o uso exclusivo desses elementos visuais é capaz de transmitir a mensagem com louvor - e é devido a isso que às vezes nos deparamos com uma fotografia ou ilustração rotulados como poesia visual.

\subsection{Algumas experimentações}

Como um exercício destas relações, experimentou-se os conceitos discutidos sobre a poesia visual contemporânea e suas conexões com o design. As experiências pessoais, o uso do espaço, a influência da caligrafia e do lettering, o trabalho de poetas visuais citados nesta pesquisa, tudo isto influenciou a criação das peças abaixo: 


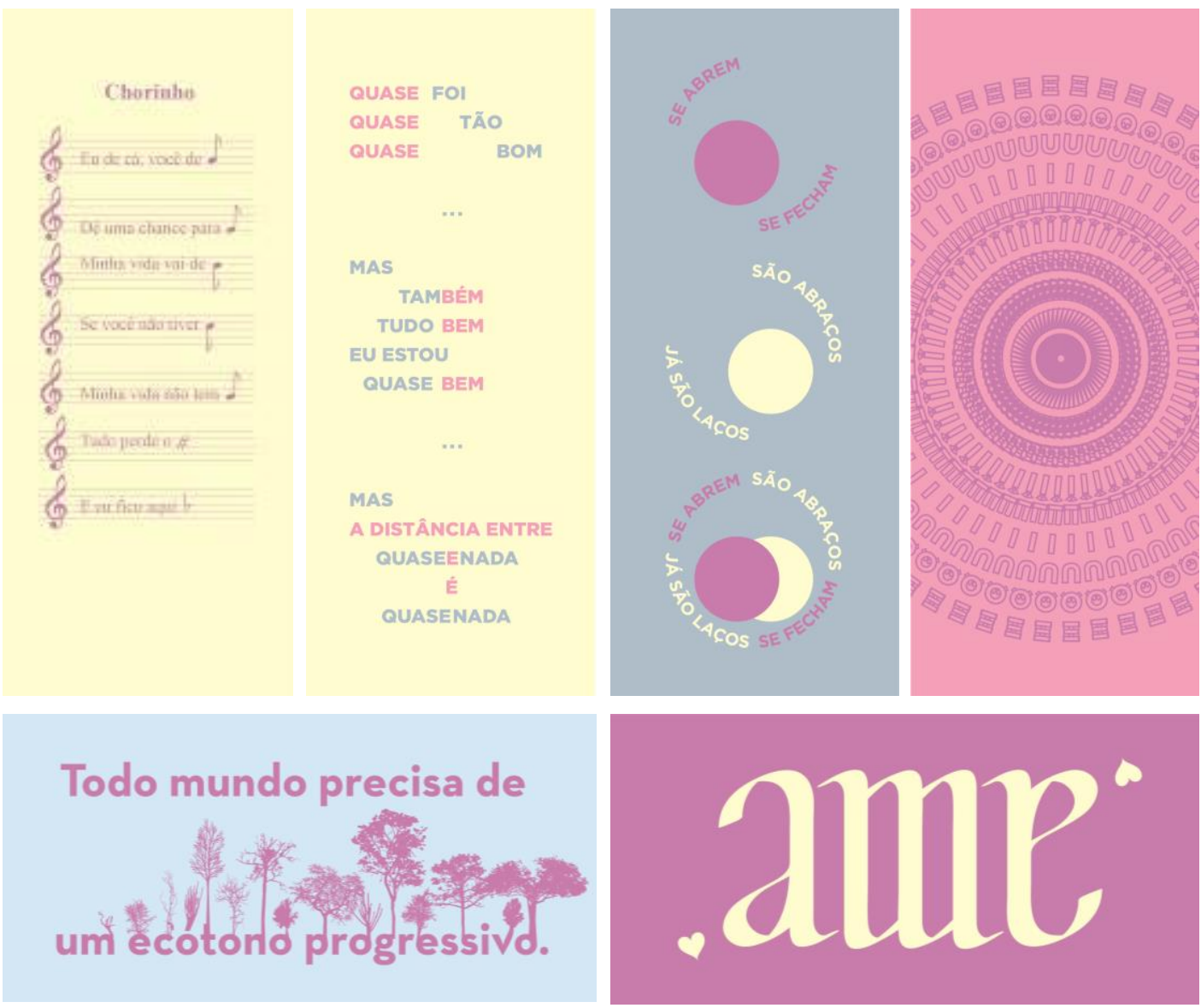

Figura 16 - As primeiras experimentações em poesia visual.

Fonte: Elaborado pelo autor, com base na pesquisa realizada.

\section{CONCLUSÃO}

Esta pesquisa não surgiu com a pretensão de encerrar a poesia intersemiótica em algumas dezenas de páginas. Ao contrário, a intenção é dar ao leitor um panorama inicial sobre o que é a poesia visual e algumas ferramentas que podem ser utilizadas na sua leitura e construção. Mais do que concluir um pensamento, esse breve estudo busca mostrar o quanto mais há a ser aprendido.

A poesia visual, como qualquer outra forma de arte, é profundamente influenciada pela tecnologia de seu tempo. A questão atual evidenciada aqui não é exatamente sobre usar bem o computador ou não, mas sim como utilizá-lo do modo mais adequado. A experimentação ainda é um caminho buscado pelos artistas da poesia intersemiótica. Nesse sentido, quanto mais o poeta puder explorar, melhor tanto as novas tecnologias (como a internet), quanto as do passado (a exemplo da caligrafia). Apesar de ser cada vez mais difícil inovar, vale o esforço.

Como uma forma de concluir esta etapa da pesquisa organizou-se o texto integral dela resultante sob o formato de um livro impresso, a fim de facilitar a consulta do seu conteúdo ao público no futuro - a publicação de tal livro é um projeto o qual se pretende dar continuidade. Além disso, para ampliar a divulgação do assunto, uma mídia digital, em formato de blog, também está atualmente disponível na internet por http em: < http://apoesiavisual.wordpress.com >, permitindo assim que o assunto permaneça em voga e constante discussão. 


\section{REFERÊNCIAS}

ACADEMY OF AMERICAN POETS. E. E. Cummings. Disponível na internet por http em: < http://www.poets.org/poet.php/prmPID/156>. Acesso em 24 abr. 2014.

AMARAL, Rui. Ruptura: documentação e história - Contexto de época. Disponível em: <http://www.artbr.com.br/casa/>. Acesso em 24 abr. 2014.

ANTONIO, Jorge Luiz. Poesia eletrônica: negociações com os processos digitais. 2005. Tese (doutorado) - Pontifícia Universidade Católica de São Paulo. Disponível na internet por http em: <http://www.cronopios.com.br/poesia eletronica.pdf $>$ Acesso em 28 abr. 2014.

CAETANO, Mariana Eller. A Escrita Icônica: design gráfico, poesia visual e seus entrelaçamentos. 2008. Pós-graduação em artes (mestrado) - Universidade Estadual Paulista, Instituto de Artes.

CAMPOS, Lílian. Poesia Visual: de Apollinaire aos concretistas. Publicado em coluna Especial para a Página 3 Pedagogia \& Comunicação. Website UOL Educação. Disponível na internet por http em: <http://educacao.uol.com.br/disciplinas/portugues/poesiavisual-de-apollinaire-aos-concretistas.htm> Acesso em 28 abr. 2014.

CAMPOS, Augusto de; PIGNATARI, Décio; CAMPOS, Haroldo de. Teoria da Poesia Concreta: textos críticos e manifestos - 1950-1960. São Paulo: Duas Cidades, 1975.

JORGE, Alana Giro et al. O dadaísmo como inspiração estética. Revista Metáforas, $\mathrm{n}$. 14, p. 1-17, 2010. Disponível na internet por http em: <http://citrus.uspnet.usp.br/ estetica/index.php/anteriores/83-revista-6/34-2011-2-art2> Acesso em 28 abr. 2014.

LUPTON, Ellen; PHILLIPS, Jennifer Cole. Novos Fundamentos do design. São Paulo: Cosac Naify, 2008.

MANIFESTO NEOCONCRETO. Jornal do Brasil, suplemento dominical de abertura da 1ạ Exposição de Arte Neoconcreta, MAM/RJ, 1959.

MEGGS, P. B. História do Design Gráfico. São Paulo: Cosac Naify, 2009.

MIRANDA, Antonio. Poesia visual brasileira na internet: uma pesquisa em andamento. In: INSTITUTO DE LETRAS DA UNIVERSIDADE DE BRASÍLIA. VIII Congresso Internacional de Humanidades, 21 out. 2005.

MÜLLER, Adalberto; DOMINGUES, Mário. Olho da letra: EE Cummings, o caligrama, a máquina de escrever e o cinema. Revista Caligrama. Revista de Estudos e Pesquisas em Linguagem e Mídia 1, no. 3, (2005). Disponível na internet por http em: <revistas.usp.br/caligrama/article/view/56682> Acesso em: 28 abr. 2014.

SCHENBERG, Mario. Concretismo e Neoconcretismo: Artigos de Mario Schenberg. 1977. Disponível na internet por http em: <http://www.eca.usp.br/nucleos/cms/index.php? 
option=com content \&view=article\&id=100: concretismo-e-neoconcretismo-

\&catid=17:artigos-de-marioshenberg\&ltemid=15> Acesso em 18 dez. 2013.

SECCHIN, Antonio Carlos. Caminhos recentes da poesia brasileira. Iberoromania, v. 1991, n. 34, p. 55-69, 1991.

SOUZA, Pedro Luiz Pereira de. $\mathbf{O}$ que foi a Bauhaus? In: Souza, Thaís. Website Mundo Estranho. Disponível na internet por http em: <http://mundoestranho.abril.com.br/ materia/o-que-foi-a-bauhaus> Acesso em 19 mai. 2013.

TEIXEIRA, A. A linguagem visual na poesia concreta. 1997. Relatório final (graduação) - Universidade Estadual Paulista "Júlio de Mesquita Filho".

KHOURI, Omar. Noigandres e Invenção: revistas porta-vozes da Poesia Concreta. FACOM - no 16 - 2o semestre de 2006. Disponível na internet por http em: <http://www.faap.br/revista faap/revista facom/facom 16/omar.pdf> Acesso em 24 abr. 2014.

KHOURI, Omar. Entrevista [mensagem pessoal]. Mensagem recebida por < amanda tmr@hotmail.com > em 29 ago. 2013.

WATANABE, E. Vozes das formas na poesia concreta do Grupo Noigandres. 2009. Pós-graduação em Artes Visuais (mestrado) - Universidade Estadual Paulista, do Instituto de Artes. 